\title{
1. Some problems with the aggregate production function
}

The production function has been a powerful instrument of miseducation.

(Joan Robinson, 1953-54, p. 81)

\section{INTRODUCTION}

The heart of the neoclassical theory of production and price theory is the concept of the plant, or firm, production function. In its simplest form it expresses the maximum or optimal amount of output that can be produced with usually two factors of production, capital and labour, measured in physical terms.

The problem of whether these individual micro-production functions can be aggregated to give an aggregate production function for the industry, or even the whole economy, is sometimes, but not often, alluded to in the literature. For example, Estrin and Laidler (1995, p. 134) note that, notwithstanding the problems of constructing unambiguous indices of the quantities of capital and labour services, 'the results of the two input/ one output special case are both useful and often capable of being generalised, and are therefore well worth the reader's attention'. Although not mentioned, there is also the problem of aggregating individual production functions with different functional forms to give an aggregate production function. Generally, the same functional form, commonly the CobbDouglas, is assumed at both the micro- and the macroeconomic levels as if one could move smoothly between the different levels of aggregation with no problems.

Unfortunately, this is not the case. There is now a large technical literature that examines the conditions under which this aggregation is possible. The results of this work conclude that these conditions are so restrictive that, as Fisher $(1969,1992)$ who has done more work on this topic than most, they are unlikely to be satisfied in reality; with the consequence that aggregate production functions most likely 'do not exist'. A more acrimonious exchange over the existence or otherwise of a well-behaved aggregate production function occurred generally in the 1960s and 1970s in the so-called 'Cambridge capital theory controversies', so named because the protagonists were based largely at Cambridge, Massachusetts, 
and Cambridge, UK. The debate could be viewed simply as a subset of the more general aggregation problem, as Fisher (2005) regards it, or as a more fundamental clash of paradigms, as Harcourt (1976) viewed it. Whatever the view taken, the capital theory controversies cast further doubt on the existence of a well-behaved production function.

In this chapter, we present a very brief overview of the substantial issues involved. It must be stressed that in this literature the micro-production functions (whether the technology has fixed coefficients or allows substitutability between capital and labour) are assumed to be well defined and unproblematic. They are very simple representations when compared with the actual production processes that occur in the real world. For example, the large differences between firms in what Leibenstein (1966) termed 'X-efficiency' are almost never mentioned and are relegated to business or industrial economics. There are strong grounds for suspecting that there are unlikely to be well-defined production functions at the plant or office level, even if we have physical data for the inputs and the outputs.

Brown (1966, p.11) provides a defence for the use of the production function largely on instrumentalist grounds:

The objection is raised that the production function is a fiction. This is sometimes expressed by the statements that engineers do not work within a production function framework, and businessmen do not consider production functions as such within the set of constraints on their decisions. Since the production function is indirectly related to the physical-technical aspects of production, it is not directly measurable, and since it is foreign to the world of common sense, it is a fiction fabricated by marginalist economists. In one sense this argument is valid. ... Yet . . the employment of production functions can be justified simply on the ground that it produces highly useful and verifiable hypotheses.

This book challenges this view.

\section{THE AGGREGATION PROBLEM: WHAT IS IT AND WHY DOES IT MATTER?}

The aggregation problem is concerned with the conditions under which it is possible to sum micro-production functions to give an aggregate relationship. This work shows that these conditions are so restrictive as to make the concept of the aggregate production function problematical in the extreme. An underlying assumption is that there are well-defined micro-production functions that can be expressed in a simple mathematical form. In other words, the fact that the output of commodities of goods or services is physically determined by the flow of inputs is uncontro- 
versial. Intuitively, we may think of an engineer designing a production process for, say, an oil refinery. The plans will indicate the efficient physical production techniques and combinations of labour (production engineers, administrative staff and so on) and physical capital (pipelines, fractionating columns, cooling towers) at different stages of the production process. The design will be dependent upon the relative scale of output and the relative costs, together with the level of technology.

Writing the micro-production function as a metaphor, a simple mathematical functional form can be used:

$$
Q=f\left(L_{1}, L_{2}, L_{i}, \ldots, K_{1}, K_{2}, K_{j}, \ldots, M_{1}, M_{2}, M_{k}\right),
$$

where $Q$ is the volume of homogeneous output measured in physical terms, and $L, K$ and $M$ are the flows of labour services, physical heterogeneous capital services (broadly defined to include buildings and so on), proxied by capital stocks and materials. For practical purposes, the metaphor for these complex production processes of the firm is given by the familiar equation for a production function: $Q=A f(L, K)$ where $Q$ is the maximum amount of output (number of homogeneous 'widgets') that can be produced from any combination of $L$ and $K$ (where capital $K$ is measured as number of homogeneous 'leets', to use Joan Robinson's term). In other words, there is a unique mapping from $L$ and $K$ to $Q$. A necessary assumption for aggregation is that the inputs are used optimally. But already a further simplification has been made. It is assumed that, $A$ denotes the level of technology, assumed to grow exponentially over time, but which is not directly observable. ${ }^{1}$

There are two technical, or mathematical issues, at stake here. The first is: under what conditions can the individual measures of, especially, the capital stock and output, but also labour, be aggregated into a single index? The second issue is: under what conditions can the functional forms representing the individual micro-production functions be summed to give a single aggregate production function that reflects the underlying properties of the micro-production functions? The technical literature on this is quite complicated and we can do no more than give a flavour of the issues involved. An accessible discussion is to be found in Felipe and Fisher (2003, 2006).

The aggregation problem is important in order to understand why aggregate production functions are such problematic constructs. In theory, the

\footnotetext{
1 This may be modelled as a knowledge production function, as in endogenous growth theory, but we shall not consider it here for reasons of space. It does not affect our argument.
} 
production function is a representation of how a commodity (for example, a chair) is made. Output $(Q)$, labour $(L)$ and capital $(K)$, as was emphasised earlier, are measured in physical terms. The production function corresponding to the chair denoted by the superscript $i$ is, for expositional ease, $Q_{t}^{i}=f\left(L_{t}^{i}, K_{t}^{i}\right)$. We assume that there are no material inputs. (This simplifies the exposition but does not significantly affect the argument.) Each commodity (or service) that an economy produces is made up using a different production process, that is, a different technology, and with different machines and workers (and possibly with other additional inputs, different in each case). As far back as the 1940s and 1950s (Klein 1946a, 1946b; Leontief, 1947a, 1947b; Nataf, 1948; and Solow, 1955-56), economists started inquiring about the conditions under which so-called 'micro-production functions' like the one above could be 'summed up' so as to yield the aggregate production function of the form $Q_{t}=A_{t} F\left(L_{t}, K_{t}\right)$ representing the aggregate technology. This production function is supposed to show how 'aggregate output', the sum of the individual outputs, namely, carrots, chairs, ships, banking services, oil and millions of other products and services, is made up by transforming the aggregates capital and labour through the production process.

In one of the first works on aggregation, Klein (1946a) used CobbDouglas micro-production functions. He suggested that an aggregate (or strictly, an average) production function and aggregate marginal productivity relations analogous to the micro functions could be derived by constructing weighted geometric means of the corresponding micro variables, where the weights are proportional to the elasticities for each firm. The elasticities of the macro function are the weighted average of the micro elasticities, with weights proportional to expenditure on the factor. The macro revenue is the macro price multiplied by the macro quantity, which is defined as the arithmetic average of the micro revenues (similar definitions apply to the macro wage bill and macro capital expenditure). Klein's treatment of the problem, however, was rejected altogether by May (1947). Walters (1963a, pp. 8-9) also noted that Kleinian aggregation over firms had some serious consequences. The definition of the macro wage bill (that is, the product of the macro wage rate times the macro labour) is $w L=\frac{1}{n_{i}} \sum_{i=1}^{n} w_{i} L_{i}$, where $w_{i}$ and $L_{i}$ are the wage rate and homogeneous labour employed in the $i$ th firm, and $L=\prod_{i=1}^{n} L^{\alpha_{i} \Sigma \alpha_{i}}$ is the definition of the macro labour input, a geometric mean, where $\alpha_{i}$ is the labor elasticity of the $i$ th firm. In a competitive market, all firms have the same wage rate $w^{*}=w_{i}$ for all $i$. Substituting the macro labour into the definition of the macro wage bill, and substituting $w^{*}$ for $w_{i}$ yields $w=\left(w^{*} \Sigma L_{i}\right) /\left(n \prod_{i=1}^{n} L^{\alpha_{i} / \Sigma \alpha_{i}}\right)$. This implies that the macro wage rate will almost always differ from the common wage rate of the firms (similar issues apply to the prices of output 
and capital). It is therefore difficult to interpret $w$ and to see why it should differ from $w^{*}$.

Leontief (1947a, 1947b) dealt with aggregation of variables into homogeneous groups. Leontief's (1947a) theorem provides the necessary and sufficient conditions for a twice-differentiable production function whose arguments are all non-negative, to be expressible as an aggregate. The theorem states that aggregation is possible if and only if the marginal rates of substitution among variables in the aggregate are independent of the variables left out of it. For the three-variable function $g\left(x_{1}, x_{2}, x_{3}\right)$ Leontief's theorem says that this function can be written as $G\left[h\left(x_{1}, x_{2}\right), x_{3}\right]$ if and only if $\partial\left(g_{1} / g_{2}\right) / \partial x_{3} \equiv 0$ where $g_{1}$ and $g_{2}$ denote the partial derivatives of $g$ with respect to $x_{1}$ and $x_{2}$, respectively. That is, aggregation is possible if and only if the marginal rate of substitution between $x_{1}$ and $x_{2}$ is independent of $x_{3}$. In general, the theorem states that a necessary and sufficient condition for the weak separability of the variables is that the marginal rate of substitution between any two variables in a group be a function only of the variables in that group, and therefore independent of the value of any variable in any other group.

In the context of aggregation in production theory (in the simplest case of capital aggregation), the theorem means that aggregation over capital is possible if and only if the marginal rate of substitution between every pair of capital items is independent of labour. Think of the production function $Q=Q\left(k_{1}, \ldots, k_{n}, L\right)$. This function can be written as $Q=F(L, K)$, where $K=\varphi\left(k_{1}, \ldots, k_{n}\right)$ is the aggregator of capital, if and only if $\partial\left[\left(\partial Q / \partial k_{i}\right) /\left(\partial Q / \partial k_{j}\right)\right] / \partial L=0$ for every $i \neq j$. That is, the theorem requires that changes in labour, the non-capital input, do not affect the substitution possibilities between the capital inputs. This way, the invariance of the intra-capital substitution possibilities against changes in the labour input is equivalent to the possibility of finding an index of the quantity of capital. This condition seems to be natural, in the sense that if it were possible to reduce the $n$-dimensionality of capital to one, then it must be true that what happens in those dimensions does not depend on the position along the other axes (for example, labour).

Note that Leontief's condition is for aggregation within a firm, or within the economy as a whole assuming that aggregation over firms is possible. Is Leontief's condition stringent assuming aggregation over firms? It will hold for cases such as brick and wooden buildings, or aluminium and steel fixtures. But most likely this condition is not satisfied in the real world, since in most cases the technical substitution possibilities will depend on the amount of labour. Think for example of bulldozers and trucks, or oneand two-ton trucks. In these cases no quantity of capital in general can be defined (Solow, 1955-56, p. 103). 
Solow argued that there is a class of situations where Leontief's condition may be expected to hold. This is the case of three factors of production partitioned into two groups. For example, suppose $y_{j}=f^{j}\left(x_{0 j}, x_{j}\right)$, $j=1,2$ where $x_{j}$ is produced as $x_{j}=g^{j}\left(x_{1 j}, x_{2 j}\right)$, so that the production of $y_{j}$ can be decomposed into two stages: in the first one $x_{j}$ is produced with $x_{1 j}$ and $x_{2 j}$, and in the second stage $x_{j}$ is combined with $x_{0 j}$ to make $y_{j}$. An example of this class of situations is that $x_{1 j}$ and $x_{2 j}$ are two kinds of electricity-generating equipment and $x_{j}$ is electric power. In this case, the $g^{j}$ functions are capital index functions (Brown, 1980, p. 389). ${ }^{2}$

We immediately run into the problem that if $Q$ and $K$ are not measured in homogeneous units, then how do we aggregate heterogeneous measures? But let us pass this by for the moment and regard capital as being measured in common units of leets, and output as numbers of widgets. In this aggregation process, it is important to emphasise that the function $F$ has to be what economists refer to as 'well behaved', that is, with positive and diminishing marginal products.

To understand what an aggregate production function is, one must understand what the aggregation problem involves. The issue is how economic quantities are measured, in particular those quantities that represent by a single number a collection of heterogeneous objects; in other words, what is the legitimacy of aggregates such as investment, GDP, labour and capital in the context of production theory?

Consider the following problem. Suppose we have two production functions $Q^{A}=f^{A}\left(K_{1}^{A}, K_{2}^{A}, L^{A}\right)$ and $Q^{B}=f^{B}\left(K_{1}^{B}, K_{2}^{B}, L^{B}\right)$ for firms A and B. Define $K_{1}=K_{1}^{A}+K_{1}^{B}, K_{2}=K_{2}^{A}+K_{2}^{B}$ and $L=L^{A}+L^{B}$ (where $K$ refers to capital - two types - and $L$ to labour which is assumed to be homogeneous). The problem is to determine whether and in what circumstances there exists a function $K=h\left(K_{1}, K_{2}\right)$ where the aggregator function $h(\bullet)$ has the property that:

$$
G(K, L)=G\left[h\left(K_{1}, K_{2}\right), L\right]=\Psi\left(Q^{A}, Q^{B}\right)
$$

and the function $\Psi$ is the production possibility curve for the economy.

It will be noted that above we have already assumed that a production function exists at the level of the firm. If an enterprise assigns the use of its various factors to different techniques of production so as to maximise output, then maximised output will depend only on the total amount of such factors, and that dependence can be written as a functional relation-

\footnotetext{
2 However, if there are more than two groups, Gorman (1959) showed that not only must the weak separability condition hold, but also each quantity index must be a function homogeneous of degree one in its inputs. This condition is termed 'strong separability'.
} 
ship. However, if the outputs and inputs are measured in physical units, this is likely to be a very complex function form as in our example of the oil refinery above. However, whether firms do maximise output is another (empirical) question. Leibenstein (1966), as we mentioned above, provides the classic evidence that they do not, as does much of the business studies literature. See, for example, the seminal study of Cyert and March (1963 [1992]). This does not mean that one can necessarily aggregate over factors. This is just one part of the aggregation problem. The other one is aggregation over firms - aggregation where factors are not all efficiently assigned.

Fisher, among others, worked out in the 1960s, 1970s and 1980s very comprehensively different aspects of the problem (see the collected papers in Fisher, 1992). The conclusion is that the conditions under which aggregate production functions can be derived by aggregating microproduction functions are so stringent that it is difficult to believe that actual economies satisfy them. For example, a labour aggregate $L$ (to aggregate workers of different types) will exist if, and only if, a given set of relative wages induces all firms to employ different types of identical workers in the same proportion. Note that this condition requires the complete absence of specialisation in employment. Similarly, where there are many outputs, an output aggregate will exist if and only if a given set of relative output prices induces all firms to produce all outputs in the same proportion. This condition requires the absence of specialisation in production: all firms must produce the same market basket of outputs differing only in their scale. And finally, aggregate production functions exist if and only if all micro-production functions are identical except for the capital-efficiency coefficient. It is important to note that these conditions are derived under the assumption of constant returns to scale. Outside this case, it is virtually impossible to derive aggregation conditions. Are these conditions true in the real world? It is highly implausible that they are. They mean that, for all practical purposes, aggregate production functions do not exist, as they are constructs without sound theoretical foundations.

To see what the aggregation problem involves, consider the following simple case. If one could simply add the machines, and the exponents of the production functions were the same across firms, then we could construct an aggregate production function provided that certain optimising conditions are assumed. It is useful to digress briefly on this point. Consider two firms each exhibiting a Cobb-Douglas production function with identical exponents, and assume for the moment that capital is homogeneous (all are heroic and implausible assumptions, to say the least):

$$
Q_{1}=A L_{1}^{\alpha} K_{1}^{(1-\alpha)},
$$




$$
Q_{2}=A L_{2}^{\alpha} K_{2}^{(1-\alpha)}
$$

The crucial assumption is that aggregate output is optimised so that the maximum level of aggregate output $\left(Q^{*}\right)$ as well as the optimised wage rate $\left(w^{*}\right)$ and profit rate $\left(r^{*}\right)$ are obtained. If we did not impose this condition, and we summed arithmetically, we would have:

$$
Q=Q_{1}+Q_{2}=A\left(L_{1}^{\alpha} K_{1}^{(1-\alpha)}+L_{2}^{\alpha} K_{2}^{(1-\alpha)}\right),
$$

which is a linear homogeneous production function, but is not a CobbDouglas. Moreover, it is not really an aggregate production function as the various inputs enter into the function separately.

Therefore, it is also assumed that the individual firms are technically efficient. This assumption implies that for each individual firm:

$$
\begin{aligned}
& \frac{\partial Q_{i}^{*}}{\partial L_{i}}=w^{*}=\alpha \frac{Q_{i}^{*}}{L_{i}} \quad(i=1,2) \\
& \frac{\partial Q_{i}^{*}}{\partial K_{i}}=r^{*}=(1-\alpha) \frac{Q_{i}^{*}}{K_{i}} .
\end{aligned}
$$

Let us assume that the output of firm 1 is some arbitrary multiple $(n)$ of the output of firm 2, that is, $Q_{1}^{*}=n Q_{2}^{*}$. As $w_{1}^{*}=w_{2}^{*}$ and $r_{1}^{*}=r_{2}^{*}$, it follows from equations (1.3) and (1.4) that $L_{1}=n L_{2}$ and $K_{1}=n K_{2}$. This is not a surprising result, as faced with a common set of factor prices, the two firms will have the same capital-labour ratios. If we now arithmetically sum the two micro-production functions, we obtain:

$$
\begin{aligned}
Q^{*}=Q_{1}+Q_{2} & =A(1+n)^{\alpha} L_{1}^{\alpha}(1+n)^{(1-\alpha)} K_{1}^{(1-\alpha)} \\
& =A L^{\alpha} K^{(1-\alpha)}
\end{aligned}
$$

where $L=(1+n) L_{1}$ and $K=(1+n) K_{1}$. This is now an aggregate CobbDouglas production function. This merely demonstrates why in practice we should not expect to find that an aggregate Cobb-Douglas production function exists, even if there are well-defined micro Cobb-Douglas production functions.

First, the derivation above depends on the assumption of competitive markets and the fact that inputs are efficiently allocated between firms as well as used technically efficiently within the firm. This is unlikely to occur given the presence of oligopolistic market structures and that individual firms are likely to be subject to substantial 
$\mathrm{X}$-inefficiencies. Second, it is implausible that firms have identical production functions.

Alternatively, from equations (1.3) and (1.4) we can calculate the geometric mean of the two firms' production functions as:

$$
\sqrt{Q_{1} Q_{2}}=A\left(\sqrt{L_{1}^{\alpha} L_{2}^{\alpha}}\right)\left(\sqrt{K_{1}^{(1-\alpha)} K_{2}^{(1-\alpha)}}\right),
$$

and measure total output as:

$$
Q=2 \sqrt{Q_{1} Q_{2}}=A L^{\alpha} K^{(1-\alpha)},
$$

where $Q=2 \sqrt{Q_{1} Q_{2}}, L=2 \sqrt{L_{1} L_{2}}$ and $K=2 \sqrt{K_{1} K_{2}}$ and which may be generalised to $n$ firms. However, output and input data for individual products or firms are not calculated in, say, the national income and product accounts or the census of production in this way.

Consequently, to summarise, there are a number of reasons for anticipating that the aggregate Cobb-Douglas production function will not give a good fit to the generated data. First, the exponents of the individual Cobb-Douglas micro-production functions differ. Second, capital is firm specific and not allocated optimally between firms. Third, the heterogeneity of the capital stock means that an index of capital has to be constructed, with the attendant aggregation problems. Moreover, the data are summed arithmetically to give the aggregate variables.

Finally, we have the intractable problem that for much of the service sector there are no unambiguous physical or indeed constant-price value measures of output - just think of the health service, education, government administration, defence and so on.

Wilson (2009) provides a test of the Leontief-Solow-Fisher conditions for the existence of a single aggregate capital stock, for any unit of production (firm, industry, economy), formed of separate quantities of heterogeneous capital. Wilson focuses on the relationship between heterogeneous capital services and productivity at the firm level. The paper first derives an empirical, firm-level production function specification incorporating heterogeneous capital services based on standard neoclassical production theory.

Wilson then directly tested the Leontief-Solow-Fisher conditions for a single aggregate capital stock. The ability to express a firm's total capital services with a single measure, even if that measure weights heterogeneous capital goods by their relative marginal products, requires that individual capital services each be weakly separable with labour (Solow, 1955-56) and that their services be expressed in common units (Fisher, 1965). These 
two conditions together require that different capital services be perfectly substitutable. These conditions have long been viewed by many economists as unrealistic. Solow himself, referring to the first of the two, commented that it 'will not often be even approximately satisfied in the real world' (1955-56, p. 103).

Wilson's results strongly rejected both conditions. First, he found strong evidence of complementarities and substitutabilities between capital types. In fact, there seems to be a particular pattern in these complementarities and substitutabilities: using any reasonable division of types of capital into 'high-tech' and 'low-tech' categories, the data indicate that high-tech capital goods tend to be complementary with low-tech capital goods, and substitutable with other high-tech capital. He also found complementarities and substitutabilities between a number of capital types and labour. For instance, software was found to be especially labour saving, while general-purpose machinery and trucks were especially labour augmenting.

It is important to emphasise that the aggregation problem does not deny that output and inputs are linked. Certainly, a chair is made with labour, capital and intermediate materials. And we are not saying either that aggregate output $(Q)$ does not exist when measured in constant-price value terms. Aggregate output is the sum of private consumption, investment, government expenditures and net exports (from the demand side of the economy). Rather, the implication of this discussion is that the representation of an economy's aggregate technology as $Q_{t}=F\left(L_{t}, K_{t}\right)$ is fictitious. There is no such a thing as the physical output of the economy $(Q)$ from the point of view of neoclassical production theory, that is, a function that transforms aggregate capital $(K)$ and aggregate labour $(L)$ into aggregate output $(Q)$.

It is instructive to quote Fisher (2005, pp.489-90) on the conclusions that can be drawn from this work:

Briefly, an examination of the conditions required for aggregation yields results such as:

- Except under constant returns, aggregate production functions are unlikely to exist at all.

- Even under constant returns, the conditions for aggregation are so very stringent as to make the existence of aggregate production functions in real economies a non-event. This is true not only for the existence of an aggregate capital stock but also for the existence of such constructs as aggregate labour or even aggregate output.

- One cannot escape the force of these results by arguing that aggregate production functions are only approximations. While, over some restricted range of the data, approximations may appear to fit, good approximations 
to the true underlying technical relations require close approximation to the stringent aggregation conditions, and this is not a sensible thing to suppose.

In retrospect, these conclusions are hardly surprising. Take a simple example, the retail sector and the production function of a supermarket. Capital includes the structures, in other words, the buildings. If one were to increase the size of the building by a certain fraction, does it make sense to ask the question: how many check-out workers could be saved? Consider, a check-out till. The process of registering the cost of the purchases is clearly fixed technology - one check-out worker per till. But now technology has developed so that there are automated check-out tills, so there is technology that makes the elasticity of substitution between the check-out machine and the cashier infinite. Yet both procedures are used due to customer preferences, so even in this very narrow case there are 'production' processes producing identical output services, but with very different elasticities of substitution. So what sense does an aggregate elasticity of substitution between check-out machines and cashiers make in even this limited case? Even the smallest plant or office is likely to consist of a range of techniques with different elasticities of substitution and hence there are problems of aggregation even here.

\section{THE CAMBRIDGE CAPITAL THEORY CONTROVERSIES}

While the aggregation problems deal with issues aggregating both inputs (of all types) and production functions at different levels, the scope of the Cambridge debates is different. The Cambridge capital theory controversies, as the name suggests, were concerned with the theoretical problems of aggregating heterogeneous individual capital goods into a single index that could be taken as a measure of 'capital' as a factor input. Perhaps a useful and clarifying way to think about the Cambridge debates and the aggregation problem is to consider whether the problem of measuring capital relates to the interdependence of prices and distribution (the Cambridge-Cambridge debates), or whether it emerges out of the need to justify the use of the neoclassical aggregate production function in building theoretical models, and in empirical testing (the aggregation problem). Both problems can be present at once, of course, but they are not the same. Also, the Cambridge debates extended to other macro debates, such as the determinants of the interest rate, the causality between savings and investment, and so on, which we do not deal with here. 
The debate started in earnest in the 1950s, and went through much of the 1960s and up to the mid-1970s, although its origins can be traced back to the Classical economists. The outcome was that it was agreed that no such index could be satisfactorily constructed (Harcourt, 1972; Cohen and Harcourt, 2003, 2005). The debate further showed that, when comparing steady-state economies, there is no necessary inverse monotonic relationship between the rate of profit and the capital-labour ratio, as in the neoclassical schema, outside of the restrictive one-sector model. In other words, the standard results from the aggregate production function as taught in the introductory textbooks could not be generalised to a multisector world. The main results are referred to as 'reswitching' and 'capital reversing'.

There is not space to go into the Cambridge capital theory controversies in detail here. ${ }^{3}$ In this book, we are primarily interested in the problems affecting the use of the aggregate production function and hence our attention is primarily focused on the problems posed by the Cambridge controversies for the aggregate production function, per se, rather than the wider methodological implications.

\section{The Problem of Measuring Capital}

The problems of the measurement of capital had been known to the Classical economists (for example, Ricardo, 1821; Wicksell, 1893), but it was not until the early 1950s that Joan Robinson began to ask some awkward questions concerning the meaning and measurement of capital that the issue became prominent. It was her 1953-54 article 'Production Function and the Theory of Capital' that largely set the scene for the subsequent capital theory debate.

Joan Robinson was particularly critical of the use of the aggregate production function and the marginal productivity theory of distribution to determine factor returns and hence distributive shares, using what we may call the John Bates Clark neoclassical parable. The two awkward

\footnotetext{
3 They have been chronicled by Harcourt (1972), Cohen and Harcourt (2003, 2005), Pasinetti and Scazzieri (2008), and Lazzarini (2011), all of whom find the Cambridge, UK arguments convincing, and by Bliss (1975) and Bliss in Bliss et al. (2005) who found them less so. Recent assessments also are provided by Birner (2002), who provides both a survey of the more recent developments and a methodological assessment. Bliss et al. (2005) is the definitive three-volume collection of 77 of the key articles on the subject. Dow (1980) and Cohen (1984) provide methodological assessments of why the outcome of the debate failed to have any lasting effect on the economics profession. After the mid-1970s, the impact of the Cambridge capital theory controversies waned: the economics profession lost interest and it was business as before.
} 
questions that Robinson asked were as follows. First, in what units is (aggregate) capital to be measured if it is to be used, along with labour and the level of technology, within the confines of the aggregate production function to determine the level of output? Second, is it possible to find a measure of the value of capital that is independent of the way output is distributed between the factors of production, labour and capital? If the aggregate neoclassical approach needs the rate of profit (or what comes to the same thing, the rate of interest in long-run equilibrium) to construct an index of capital, as Robinson argued it does, how can we use this 'measure' in the form of capital's marginal product to determine the rate of return to capital? For Robinson (1956), these were not rhetorical questions and her Accumulation of Capital is an attempt to find an answer.

One way to measure the capital stock could be to calculate its net present value. If the returns to a machine measured in monetary units were known, then its net present value could be estimated as the discounted stream of its net earnings. But this was not a satisfactory answer to Robinson's question, as it is necessary to begin by taking the rate of interest (the discount rate) as given, which is precisely what she wished to determine. There is a lack of causality which Cambridge, UK, took to be important: in order to determine the rate of profit, it is necessary to know the value of capital, but to determine the value of capital, it is necessary to use the rate of interest.

Rather than this 'forward-looking' measure of capital, capital goods could be valued by their cost of production. One approach, Robinson (1953-54, p. 82) suggested, was to measure capital in terms of wage units, 'that is, in effect, to measure their cost in terms of a unit of standard labour'. But there are problems here: labour makes machines with other machines and so 'the cost of capital includes the cost of capital goods, and since they must be constructed before they can be used, part of the cost of capital is interest over the period of time between the moment when work was done in constructing capital goods and the time they are producing a stream of output' (p. 82).

The response of the neoclassical economists to this line of argument was that Robinson had failed to understand the nature of a simultaneous equation system. This was the view of, for example, von Weizsacker (1971, pp. 97-8) and Stiglitz (1974). Harcourt's (1976) response was brief and to the point. It was that it is difficult to see how anyone familiar with the work of Joan Robinson, Kaldor and Sraffa could argue that they did not know about simultaneous equations:

When marginal products are spoken of as key determinants of equilibrium values, what is meant is that the relationships which are being partially differentiated in order to obtain the marginal products need to be technical 
relationships, formally akin to psychological ones like utility functions, so that they exist before, and are independent of, the equilibrium values which are the solutions of the sets of simultaneous equations. (The equalities (or inequalities) themselves between (say) marginal products and equilibrium prices are characteristics of the equilibrium solutions. They are therefore the consequences of the ultimate causes - preferences, technical endowments, and maximising behaviour. Yet even though there has been looseness of expression, the thrust of the argument is perfectly clear.) Clearly, the marginal product of 'social' or aggregate 'capital' cannot be fitted into this mould because it cannot be measured in a unit which is independent of distribution and prices. (Ibid. p. 37, omitting a footnote, emphasis in the original)

Joan Robinson, at least in the early years, was not nihilistic in her conclusions as to the possible usefulness of the aggregate production function. Although she argued that it 'has a very limited reference to actual problems', Robinson (1953-54, p. 100) did concede the 'platitude' that if in a country 'more capital had been accumulated in the past relative to the labour available for employment, the level of real wages would probably have been higher and the technique of production more mechanized, and, given the amount of capital accumulated, the more mechanised the technique of production, the smaller the amount of employment would have been', a concession Sen (1974, p. 334) readily seized on.

There is a methodological parting of the ways over the aggregate production function. The neoclassical path takes the view that any theory is a necessary abstraction from reality, with the assumptions emphasising the key factors with which the model is concerned. Different models may be needed to analyse different aspects of a class of problems. Indeed, as Joan Robinson herself said, a map on a scale of one to one is of no use to anybody. Just as Newtonian physics is only an approximation, it is perfectly satisfactory for introductory mechanics courses, so 'similarly, an aggregative growth model may do perfectly well in explaining long-term movements in certain macroeconomic variables' (Stiglitz, 1974, p.901). This is adopting an almost instrumentalist view of science, where predictive ability is the deciding criterion of the usefulness of a theory.

The second path argues that one cannot have a theory that is logically flawed. This was the view of, for example, Sraffa who remarked at the 1958 Corfu conference on capital theory (Lutz and Hague, 1961, p. 305) 'theoretical measures [require] absolute precision'. If a theory can be shown under some circumstances to have perverse results, then one cannot continue as if these were non-existent or empirically trivial. 


\section{Samuelson's Surrogate Production Function and Reswitching and Capital Reversing}

As noted above, the problems of the valuation and measurement of capital had been debated since the time of the Classical economists. However, it was paradoxically Samuelson's (1962) attempt to show that the one-sector aggregate production function could be viewed as an acceptable approximation, or 'parable', to a world where there are heterogeneous capital goods that led to the debate in the mid-1960s that attracted the attention of the wider community of economists. Ironically, the eventual outcome was the opposite of that put forward by Samuelson.

Samuelson posed the following question: given the properties of the one-sector aggregate production function with homogeneous physical capital goods, could it be a useful approximation, or parable, for a more complex set of underlying technical relationships with heterogeneous capital goods? For a short time, Samuelson thought he had succeeded in proving that this was indeed the case with his 1962 paper on the surrogate production function. A core relationship of his analysis was the factorprice frontier or the wage-profit rate frontier and so it is useful to derive it in the context of the one-sector model.

The aggregate production function (assuming, for expositional ease, no technical change) is theoretically given by:

$$
Q=F(L, K),
$$

where $Q, L, K$ are the numbers of units of output, identical employees, and the physical units of capital (measured in, say, 'leets'), respectively. For consistency, $L$ and $K$ should be the flow of services provided by the stocks of labour and capital, but, as is usual in the literature, we shall assume that they are in fixed proportion to $L$ and $K$ and ignore the complication.

We may write the aggregate production function, under the assumption of constant returns to scale, in per capita terms as:

$$
q=f(1, k),
$$

where $q=Q / L$ and $k=K / L$. As we are dealing with a one-sector model, the value of the capital is in homogeneous physical units, but the implicit assumption is that this can also uniquely represent heterogeneous capital goods valued by their rental prices, and hence expressed in value terms.

Whether this is the case or not is at the heart of the capital theory controversies. From the usual optimisation assumptions, the optimal 
capital-labour ratio will occur where the isocost line, namely, $q=w$ $+r k$, is tangent to the production function. In Figure 1.1(a), for the capital-labour ratio $k_{1}$, this occurs at point $a$. It can be seen that as the wage rate falls and the rate of profit increases, the point of tangency moves along the production function to the right. For example, at the higher capital-labour ratio, $k_{2}$, this occurs at point $b$. It follows that there is a monotonic inverse relationship between the rate of profit and the capital-labour ratio (see Figure 1.1(b)) and a positive monotonic relationship between the wage rate and the capital-labour ratio (Figure 1.1(c)).

The isocost line can be expressed as the linear equation, $w=q-r k$, which represents the wage-profit rate trade-off. At point $a$ in Figure 1.1(d), the capital-labour ratio is $k_{1}$ and the wage-profit rate trade-off is $w_{1}=q_{1}-$ $r_{1} k_{1}$. This is depicted again by the line AA. As the capital-labour ratio increases, it can be seen from Figure 1.1(a), the rate of profit falls, and so a linear wage-profit rate trade-off at the greater capital-labour ratio $k_{2}$ is given by the line BB in Figure 1.1(d). Consequently, the envelope of the wage-profit rate trade-off, or the wage-profit rate frontier, is the concave function depicted in Figure 1.1(d).

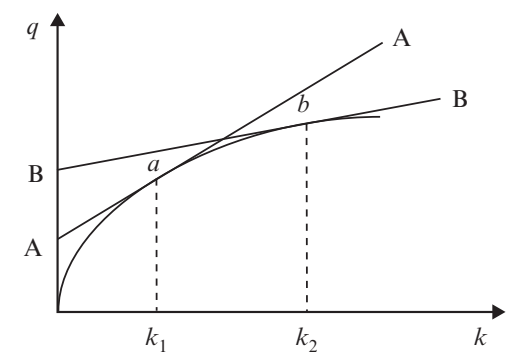

(a) The production function in intensive form

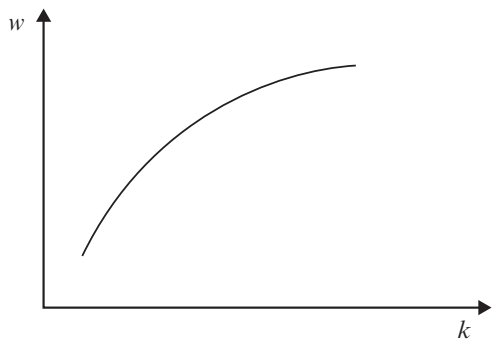

(c) The relationship between the wage rate and the capital-labour ratio.

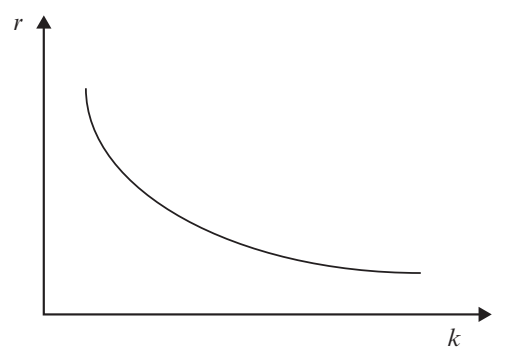

(b) The relationship between the rate of profit and the capital-labour ratio

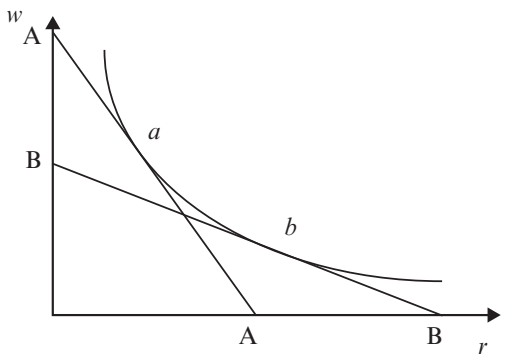

(d) Factor price or wage-profit rate trade-off

Figure 1.1 The one-sector aggregate production function 
The slope of the wage-profit rate frontier at any point is given by the capital-labour ratio, and the measure of the quantity of capital does not alter with variation in the wage and rate of profit. In other words, the index of capital behaves as if capital were measured in physical units of 'leets'.

At the risk of repetition, we may summarise the results as follows:

- The rental price of capital (and rate of profit) declines with an increase in the capital-labour ratio, but at a decreasing rate, because of diminishing returns.

- The wage rate increases with an increase in the capital-labour ratio, but at a decreasing rate.

- From the above two results, it follows that there is an inverse relationship between the wage rate and the rental price of capital (and rate of profit) which is the factor-price frontier (or the wage-profit trade-off).

- At any point on the factor-price frontier, the slope of the curve is equal to the capital-labour ratio.

- The elasticity of the factor-price frontier equals the ratio of the factor shares (and the output elasticities). ${ }^{4}$

These results hold for a one-sector model and the key question is whether or not they can be generalised to the case where there are heterogeneous capital goods. In other words, can the results from the one-sector model act as an approximation, or a parable, for the more complex underlying technology? This is what Samuelson (1962) thought, erroneously as it turned out, that he had shown.

Samuelson assumed that a good can be made from a single technique 1 , which comprises two separate production relationships. The first is for the production of the consumption good, say, corn which is produced by a specific capital good, for example, a plough and labour. The second, again with a fixed-coefficients technology, produces the plough using labour and ploughs. But technique 2 could use an entirely different capital good. As Samuelson put it 'any one capital good, call it alpha, looks entirely different from a second beta capital good. Thus, think of one as a plough; another as a machine tool or loom, or as a much more "mechanized" plough. No alchemist can turn one capital good into another' (p. 196).

4 To these results, Cohen and Harcourt (2005, p. xxxi) add that the approach grounds the 'return on capital (rate of interest) in the natural or technical properties diminishing marginal productivity of capital or roundabout production' and it explains 'the distribution of income between capitalists and labourers from a knowledge of relative factor scarcities/supplies and marginal products'. 
It is assumed that there is perfect competition, and so the wage rate and the rate of profit are the same in both sectors. Instead of using two prices, one for corn and the other for machines, the price of corn is chosen as the numéraire and is set equal to unity. The equations for the two techniques of production may be solved to give a single relationship between the real wage rate and the profit rate. In other words, it is a single wage-profit rate trade-off. (See, for example, Jones (1975, ch. 4) and Lazzarini (2011, ch. 3) for formal expositions of this derivation.)

For expositional ease (but it actually turns out to be crucial for the results), Samuelson assumed that the capital intensities were the same in the consumption and the machine-good industry, which gives a straightline wage-profit rate trade-off for each technique. Thus, if we take the wage-profit rate ratios for the various techniques, 1, 2, 3, and so on, we find that the envelope of these lines (the wage-profit rate trade-offs) takes a concave form similar to that given by the one-sector model. Consequently, if a continuum of different techniques exists, then we have arrived at the same predictions as the one-sector aggregate production which incorporates malleable homogeneous capital. Hence, this provides the rationale for Samuelson's contention that the aggregate production function may be seen as a parable for an economy with heterogeneous goods.

For a brief period, Samuelson was seen as providing a compelling justification for the use of the simple aggregate production function. Even if we use discrete and different technologies and capital goods, in the steady state high wage rates are associated with high capital-labour ratios. Moreover, if a technique is profitable at a given rate of interest, but becomes unprofitable at a lower rate of interest, it can never become profitable again at an even lower rate of interest.

The problem is that Samuelson's result depends on the assumption that both sectors making up the single technique have identical capital-labour ratios. This means that, to all intents and purposes, we are still in a onecommodity world. As soon as any attempt is made to generalise this assumption, the neoclassical parable breaks down. The factor-price frontier may be concave from below, or above, and two factor-price frontiers may intersect twice. In particular, a technique may be the most profitable at a high rate of interest and a low rate of interest, while another technique may be the most profitable at intermediate interest rates - a phenomenon known as 'reswitching'.

This is shown in Figure 1.2. The top panel of the figure shows the wageprofit rate trade-off for two techniques, 1 and 2, given by the lines $\mathrm{CC}$ and DD, respectively. It can be seen that at low and high interest rates, technique 1 with the wage-profit rate line $\mathrm{CC}$ dominates, whereas at intermediate interest rates, technique 2 with the convex from above wage-profit 


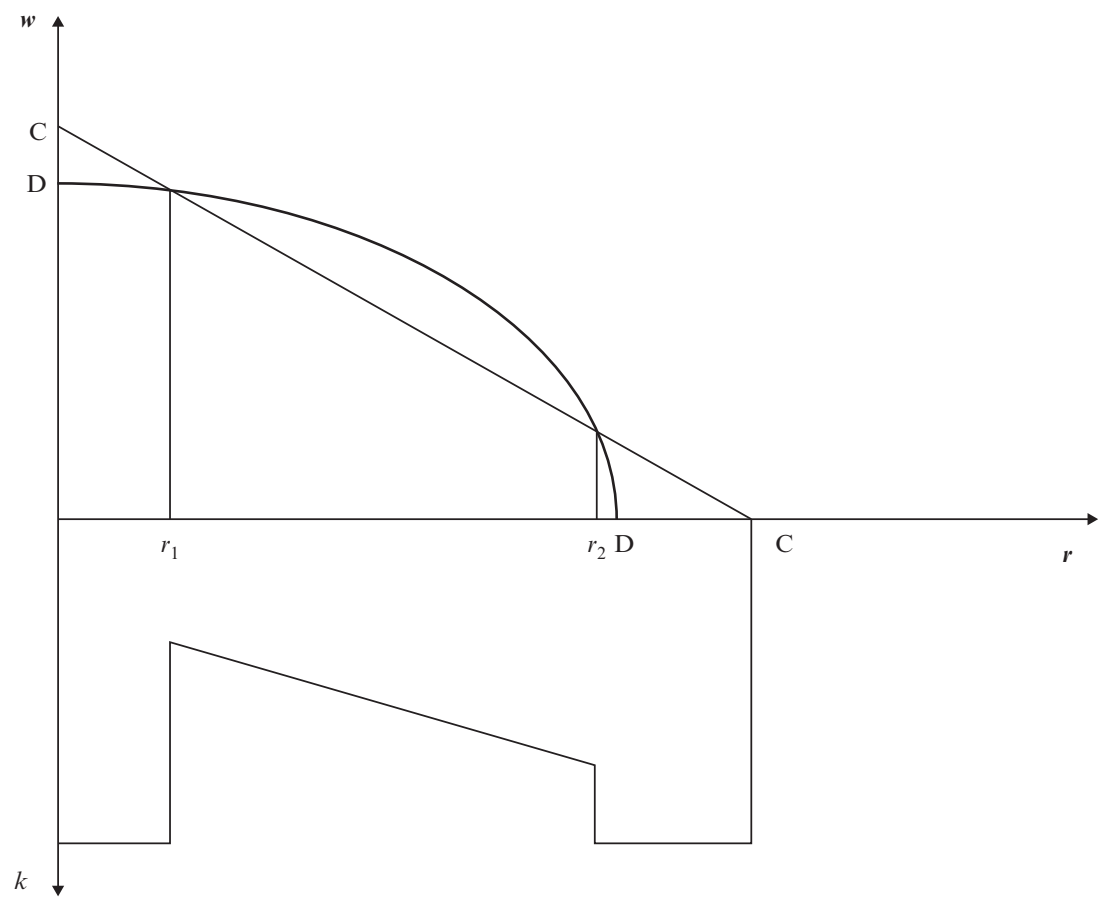

Figure 1.2 Reswitching and capital reversing

line DD is the more profitable. It is not linear because the capital intensities differ between the two sectors comprising technique 2 . The lower half of the figure shows the relationship between the value of the capital stock and the rate of interest. In the case of technique 1, it may be seen that the capital-labour ratio expressed in value terms is constant. However, with technique 2, the value of the capital-labour ratio (and hence the value of capital) varies as the rate of profit changes and there are discontinuities at $r_{1}$ and $r_{2}$. Capital reversing occurs because as the rate of profit falls and the economy switches at profit $r_{1}$ from techniques 1 and 2 , so the value of the given physical stock of capital falls. However, at the switch point $r_{2}$ the value of the capital stock now increases, reverting back to its original value (Figure 1.2, lower panel). In other words, this example is at variance with the results of the simple aggregate production function.

The importance of reswitching was really brought home when Levhari (1965) thought that he proved Samuelson's conjecture that reswitching cannot take place in a situation where every output requires every other output as an input, either indirectly or directly, into its production 
process. A symposium was held in 1965 to consider Levhari's results with the papers published in the Quarterly Journal of Economics in 1965. Levhari's conclusion, however, was shown to be false, except under a few special circumstances (see Birner, 2002, ch. 7 for a clear exposition).

Controversies often never seem to come to an unambiguous and conclusive end and this is the case with the Cambridge capital theory controversies. This is notwithstanding the summing up by Samuelson (1966), where he conceded the logical validity of reswitching. ${ }^{5}$

In the immediate aftermath of the Quarterly Journal of Economics symposium, there were further attempts to defend the neoclassical aggregate production function. See, for example, Ferguson and Allen (1970), Gallaway and Shukla (1974), Sato (1975) and Garegnani (1976). Burmeister (1977) also attempted to rescue the neoclassical position using the concept of the 'regular economy' but see Baldone's (1984) criticism. Ahmad (1991) and Birner (2002) give detailed expositions of these arguments. The latter views much of this subsequent literature as 'proof driven' with little or no economic content.

The final neoclassical response was to shift the debate into general equilibrium theory, which lies at the core of the neoclassical theory and explains prices in terms of preferences, endowments, technology and scarcity. No aggregation of capital is required. 'But the switch to general equilibrium, rather than saving the neoclassical parables, abandoned them for simultaneous equation price systems, and correct statements about factor returns being equal to or measured by disaggregated marginal products' (Cohen and Harcourt, 2003, p. 206).

There have been attempts to determine by simulations the likelihood of reswitching occurring. This, ironically, is almost entirely the preserve of the critics of the neoclassical analysis. For example, Pertz (1980) attempted to show that the likelihood of reswitching progressively declines as the number of sectors in an economy increases, but Ahmad (1991) finds no support for this - if anything, the converse is true. Mainwaring and Steedman (2000), in a simple two-sector single product scheme, find by means of simulation analysis that the probability of reswitching is very low, less than 1 per cent, although their method of determining this has been criticised by Salvadori (2000). Zambelli's (2004) simulation results confirm that the likelihood of reswitching is 'sporadic', but he finds that

In this article, he provides a very neat example of the causes of reswitching using a simple model for the production of a good using two different techniques that consist solely of different amounts of labour, which are applied at different periods of time. He shows that the same technique has the cheaper cost of production at both high and low interest rates, but not at intermediate values. (See also Cohen and Harcourt, 2003, pp. 202-3.) 
the likelihood that the capital-labour ratio is negatively related to rate of profit (that is, there is no capital reversing) is only 40 per cent. He concludes that 'for the artificial economies described here, the results indicate there is a-not-too-small [world] for which the neoclassical postulates, in particular the "real Wicksell effect" ... do not hold" (p. 115).

Petri (2000) notes that the probability of reswitching occurring in simulation models depends very much on the (arbitrary) underlying assumptions:

There is the danger that, by changing them, one may obtain nearly any result. ... Still, if one believes the kind of exercises attempted here, then the message appears to be that the Samuelson-Hicks-Garegnani model supplies no basis at all for believing that the likelihood of 'perverse' switches can be considered negligible, rather the opposite. (pp.23-4)

Han and Schefold (2006) use input-output tables for the OECD countries to test empirically the possibility of reswitching. They find that the existence of at least three switch points between two wage curves is negligible; it occurs only 0.73 per cent of the time. This would, at face value, seem to confirm the Giffen good critique of the reswitching debate - it may be theoretically correct, but of sufficient minor importance empirically that it does not invalidate the use of the surrogate production function as a good approximation to the underlying production technology of a firm or economy.

Gandolfo (2008) in a comment on Schefold's (2008) application of the surrogate production function to the CES makes a number of important points concerning the Cambridge critique, the use of input-output tables and the aggregate production function (in this case the CES). First, he questions the assumption made by both parties that the underlying techniques are linear and perfect competition prevails, which is certainly not the case for many production processes. Once the assumption of perfect competition is dropped, then the assumption that the rate of interest is identical to the rate of profit becomes untenable. The rate of interest is a component of the cost of production and prices are no longer determined as in the standard Sraffian model.

Gandolfo makes the further point that all these models assume that there can be substitutability both ex ante and ex post where, once a technique is installed, there is no substitutability. He comments:

[T]he data used, being based on real-life observations, presumably include nonlinearities and non-uniformity, as well as putty-clay phenomena. If so, they are not suitable to either confirm or disprove the theory behind the controversy. In particular, I feel that the debate on reswitching and reverse capital 
deepening makes sense only ex ante. Ex post, changes in the real wage rate (for example determined by bargains between firms and trade unions) do not lead to changes in technique, but to changes in the rate of profit, at least in the short run. (p. 799)

Consequently, while the use of the actual (rather than hypothetical) input-output tables may seem to have the advantage of being more realistic, care must be taken in interpreting the results. In fact, this comes to the same conclusion as empirical estimations of aggregate production functions using value data, which also have been used to justify their continued use. However, the input-output approach shares the same limitations as estimates of the aggregate production function. The input-output table is a snapshot in time of the various flows between industries, measured in value terms. The data include the value of materials, wages and profit and there are no prices associated with the tables, just aggregate price deflators. Furthermore, the use of value data in the input-output tables as proxies for the technical coefficients of production, which are assumed to be fixed, is not an innocuous procedure. These 'coefficients' will change with changes in wages and the rate of profit. The justification by Han and Schefold (2006, p. 750) for using monetary values is not convincing. They argue that as distribution and relative prices change little at a constant rate of profit 'monetary coefficients do reflect physical structure'. It is similar to the implicit assumption in the neoclassical production function that one can move smoothly from output and capital in terms of physical magnitudes (which is the correct specification) to one where they are measured in value terms. Indeed, it takes but a small step to argue that the good fits often obtained by estimating aggregate production functions confirm the relevance of the surrogate production function. The problem is that the coefficients of production that may be derived from an input-output table are not technological coefficients as used in the Sraffian system, but are value measures and hence suffer from the problems outlined in this book.

\section{Logical versus Historical Time}

The debate about reswitching and capital reversing concerns comparisons of steady states or comparative statics. It does not involve historical time. Cohen and Harcourt (2005) emphasise the importance of this through a simple example. Imagine the simple textbook diagram of the isoquant with labour (measured in standard hours worked) on one axis and the value of capital on the other. (It must be the value of capital given the heterogeneity of the capital goods.) The optimal choice of technique is given by the tangency of the isocost line to the isoquant. Let us take a particular solu- 
tion to this problem where the current prices are in long-run equilibrium. They have been constant in the past and will remain so for the foreseeable future. At this point all three measures of the value of capital - whether it is the cost of investment, the cost of production or the expected net present value - give the same result. Let us call this situation A. Similarly if we take another long-run situation where the factor prices are different, situation B, then again all three measures of capital are equivalent. But what happens if we are at situation $\mathrm{A}$ and then the relative prices change in historical time? As Cohen and Harcourt (p. xxxvi) put it: 'With different values of the interest rate, the net present value will no longer be equal to the initial investment or cost of production. A measure of the firm's capital can have three different quantitative values'. Moreover, the isoquant becomes incoherent as a movement along it will cause it to shift because it is not clear whether, or to what extent, the quantities of the heterogeneous capital stock or the value of capital stock are changing. Consequently, there are serious problems to the measurement of capital beyond those exposed by the reswitching debate.

\section{CONCLUDING COMMENTS}

We have only barely scratched the technical issues concerning the aggregation problems involving the aggregate production function. These suggest theoretically that the existence of the aggregate production function is highly unlikely. But in a sense, the problems are far more serious than these results suggest. This is because these arguments, damaging though they may be, still assume a very simple well-defined micro-production function at the plant or, when the output are services, organisation level. Consider the Cobb-Douglas micro-production functions or the fixed coefficients of the Sraffian system (even when proxied by input-output coefficients) and compare them with the heterogeneous labour skills and different types of capital goods, including structures, that go into the micro-production function, be it confectionery production or aircraft manufacturing, tax revenue collection or hospital services. Following Gandolfo, consider the various ex ante degrees of substitution between different types of ('putty') capital (personal computers and desks) or between labour and capital. These will differ once the capital equipment has been installed ('clay capital'). There is also substantial variation in the degree of efficiency between firms and organisations. Even if we had a complete description, or blueprint, of the various heterogeneous machines, computers, buildings and other capital goods and all the workers of different skills, or, in other words, a complete blueprint of the production process, it would be highly 


\section{The aggregate production function}

unlikely that we could find a simple mathematical equation linking the output(s) to the inputs. Actually, in most cases, it would not be a blueprint because it is a palimpsest of past investments and hirings. We shall not labour the issue, but simply point out the difficulty, or indeed impossibility, of finding any well-defined mathematical function that relates inputs to outputs even using physical measures at the microeconomic level.

It is thus all the more remarkable that, for example, Douglas (1948), in estimating the aggregate production function and relying on very crude measures of the value of the capital stock ${ }^{6}$ and numbers employed, or man-hours and using numerous cross-industry datasets, should have found such extraordinarily good statistical fits. He invariably found correlation coefficients of over 0.9 and the 'output elasticities' as near to the values of the factor shares as makes no difference. In the subsequent chapters we explain why.

6 They were seen as so problematical that shortly after Douglas published his first results the US statistical authorities ceased calculating them for many years. 